\title{
ANP AND RATINGS MODEL APPLIED TO SUPPLIER SELECTION PROBLEM
}

\author{
Amanda Cecília S. da Silva* \\ Division of Mechanical Engineering \\ Aeronautical Institute of Technology \\ São José dos Campos - SP, Brazil \\ E-mail: amanda@ita.br \\ Leila Paula A. S. Nascimento \\ Division of Mechanical Engineering \\ Aeronautical Institute of Technology \\ São José dos Campos - SP, Brazil \\ E-mail: leila@ita.br \\ Joana Ramos Ribeiro \\ Division of Mechanical Engineering \\ Aeronautical Institute of Technology \\ São José dos Campos - SP, Brazil \\ E-mail: joana@ita.br \\ Mischel Carmen N. Belderrain \\ Division of Mechanical Engineering \\ Aeronautical Institute of Technology \\ São José dos Campos - SP, Brazil \\ E-mail: carmen@ita.br
}

\begin{abstract}
The Supplier Selection Problem (SSP), for many specialists, is one of the most important functions of the purchase sector. It can be defined as the process by which suppliers are reviewed, selected and evaluated into the supply chain company context. The SSP is defined in literature as a complex decision problem because it contains multiple alternatives and multiple criteria.

This paper proposes an approach based on the Analytic Network Process (ANP) with Ratings for the final supplier selection. Ratings consist in assigning categories to previously defined criteria for alternatives selection. This approach reduces the number of judgements required for a decision and allows the analysis of cases with high number of alternatives.
\end{abstract}

Keywords: Supplier Selection Problem, ANP, Ratings.

\section{Introduction}

The globalization and the competitiveness have motivated higher attention to the Supply Chain Management (SCM) process. The SCM embraces innumerable competences. Among them, purchasing and programming of supplies competences have assumed a strategic role to reach the competitiveness advantage to many companies, especially for those that spend a high percentage of their recipes with supplies of parts and materials, and which costs represent a higher share of total costs (SAEN, 2007). Purchasing department plays a key role in reducing costs and the supplier selection is a strategic problem to be solved.

\footnotetext{
* Corresponding author

Supplier Selection Problem (SSP) is considered a complex problem in literature because it contains multiple alternatives, multiple criteria (qualitative and quantitative that may have conflict among
} 
them) and restrictions imposed by the purchasing process (SONMEZ, 2006). However, despite being a strategic question for the supply chain, in most cases, the decision to choose the supplier depends on the managers' experience, and negotiations are frequently inefficient (LEE and OU-YANG, 2008).

The importance of studies and researches around this subject is to adopt techniques that help managers to select their suppliers in a way to minimize chances of a bad selection and, consequently, negative impact over the whole organization.

This article provides an approach based on the ANP method with Ratings to solve the SSP. ANP is a discrete multiple criteria method, characterized by the decomposition of a problem in a network structure, without hierarchical relations among its elements. The method allows relations of dependence and feedback among criteria and alternatives (SAATY, 2005). The use of Ratings models is accomplished by assigning categories to previously defined criteria for selection of alternatives. This process reduces the number of judgments required to decision makers and allows the analysis of cases with high number of alternatives.

This work is structured in five sections: Section 2 presents the Supplier Selection Problem (SSP); Section 3 describes the ANP method with Ratings; Section 4 presents an illustrative example; and finally, in Section 5, final considerations.

\section{Supplier Selection Problem - SSP}

The SSP is defined by Saen (2007) as the process through which suppliers are reviewed, chosen and evaluated to be part of the supplies chain. For Güner et al. (2007) the SSP may be defined like choosing the right suppliers for certain product or groups of material. The selection process involves the determination of qualitative and quantitative factors in order to select the best suppliers. Taken as a strategic question to companies, Baily et al. (1994) apud Croom (2001) say that the selection of suppliers "is a critical decision for many organizations, once the supply performance may have financial and operational impacts in business".

The importance to select adequate suppliers and propitiate good partnerships between suppliercompany owes to the fact that the market's competitiveness does not allow a high quality production with low cost without the support of good suppliers. Hence, the selection of right suppliers may significantly reduce the acquisition costs, improve company's competitiveness and reduce the problems of material's bad quality and high delivery times (ONESIME et. al., 2004; SAEN, 2007).

Silva et al. (2008) proposed a framework (Figure 1) for the SSP based on the studies of Boer et al. $(1998 ; 2001 ; 2003)$ and Sonmez (2006). The following stages composes the proposed framework: 1) Problem definition; 2) Formulation of decision criteria; 3) Pre-qualification of potential suppliers; 4) Final suppliers selection, and; 5) Monitoring of the suppliers selected.

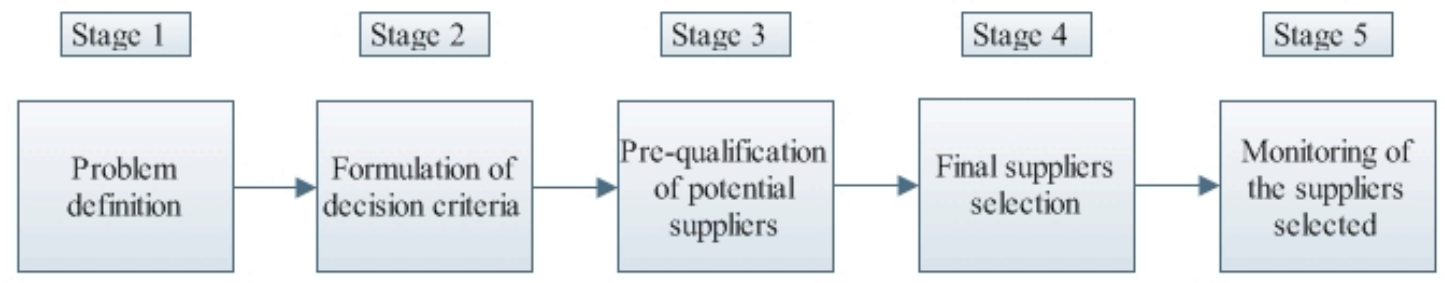

Figure 1: Framework for the SSP (Silva et al., (2008)).

Stage 1 is concerned with the problem definition and understanding. In literature, the following methods are suggested: Why What's Stopping-analyse (WWS), Cognitive Mapping, Analysis of Interconnected Decision Areas (AIDA), Strategy Generation Table, Influence Diagrams (BOER et al., 2001).

Stage 2 formulates the decision criteria. Many authors have identified criteria involved in the selection process such as Ribeiro et al., 2007. And, recently, has been treated by Korpela et al., 
(2001), Boer et al., (2001), Bello (2003), Wang et al., (2004), Bayazit (2006) and Sonmez (2006). Cheraghi et al. (2001) in his work about critical factors (criteria) for the success of suppliers selection, have identified the most important ones: quality of the product, delivery, historical performance of the supplier and the political guarantee used by the supplier. Since then, innumerable other criteria are presented in SSP articles, according to the necessities of each organization.

Stage 3 pre-qualifies potential suppliers. It aims to eliminate inefficient suppliers, reducing the alternatives available for a minor set of potential suppliers.

Stage 4 provides the final suppliers selection. This stage concentrates the vast majority of approaches used to solve SSP that exists in the literature (Boer et al., 2001). There are many methods proposed in literature, among which: the Analytic Hierarchy Process (AHP), Analytic Network Process (ANP), Fuzzy Sets Theory (FST), models mathematical programming, DEA, statistic models, models based on artificial intelligence (neural networks and expert systems), hybrid models, among others.

At last, Stage 5 monitors the suppliers selected by a continuous evaluation. This evaluation is normally made through a performance analysis. Araz and Ozkarahan (2007) proposed a method to monitor the supplier by evaluating its performance improvement and by verifying if it has reached or not the strategic level imposed.

Although all stages in the framework have their importance, this work proposes an approach for the final supplier selection based on the ANP method with ratings that will be explained in the next section.

\section{Multiple criteria decision making methods applied to SSP}

\subsection{Literature review of ANP in SSP}

Stage 4 (Final suppliers selection) consists in making a ranking of potential suppliers pre-qualified in stage 3. Most of the articles concerning SSP are concentrated in this step and many are the methods proposed for the final selection of suppliers. In the work of Silva et al. (2008) several methods are described such as: Mathematical Programming, Utility Function, AHP/ANP, DEA, Genetic Algorithm, among others.

The work of Tahriri et al. (2008) stands out that the choice of method is important for the selection process and may have significant influence over the result. Figure 2 shows the relation between the criteria and methods existing for the suppliers selection since 1960. The criteria are classified in quantitative and qualitative. The methods used to select suppliers before 2003 used only the quantitative criteria. After 2003, one began to give more attention to the qualitative criteria and, consequently, the methods for SSP solution use both criteria. Methods presented in Figure 2 are some of the suggested by Boer et al. (1998; 2001; 2003), Sonmez (2006), Tahriri et al. (2008) and Silva et al. (2008).

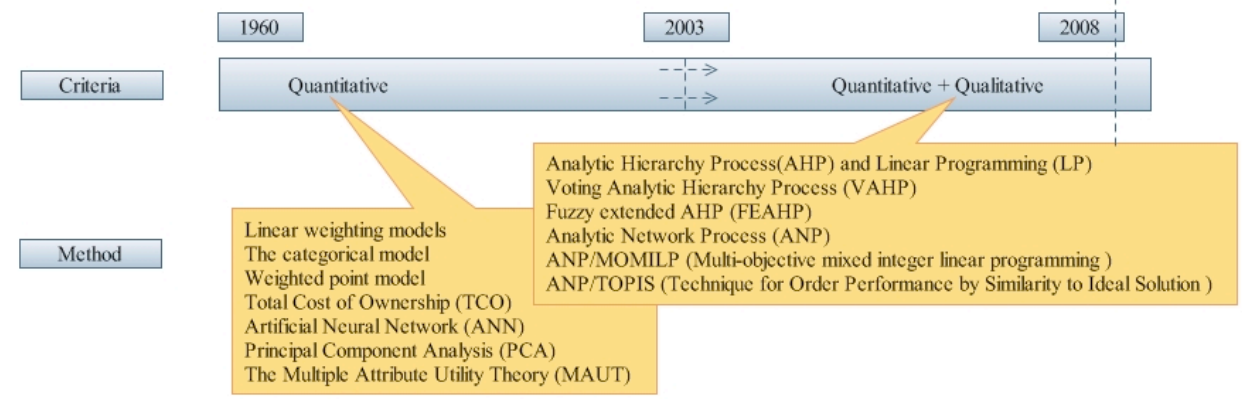

Figure 2: Relation between criteria and methods for SSP since 1960

(adapted from Tahriri et al., 2008)

Few works have been found concerning application of ANP in SSP. Nascimento et al. (2008) analysed 13 articles obtained as result of the bibliography research, according to Table 1. 
Table 1. Literature review: application of the ANP to SSP (Nascimento et al. (2008))

\begin{tabular}{|c|c|}
\hline Methods & Resume \\
\hline $\begin{array}{l}\text { Analytic Network } \\
\text { Process (ANP) }\end{array}$ & $\begin{array}{l}\text { Construction of the model and priorization of the alternatives. } \\
\text { Sarkis and Talluri (2002), Nakagawa and Sekitani (2004), Bayazit (2006), Chen } \\
\text { and Lee (2006), Gencer and Gürpinar (2007). }\end{array}$ \\
\hline $\begin{array}{l}\text { Analytic } \\
\text { Hierarchy } \\
\text { Process } \\
\text { (AHP)/ANP }\end{array}$ & $\begin{array}{l}\text { The AHP was used to build a hierarchy which helped later to build the network } \\
\text { structure. } \\
\text { Nakagawa and Sekitani (2004), Hou and Su (2005). }\end{array}$ \\
\hline $\begin{array}{l}\text { ANP/Technique } \\
\text { for Order } \\
\text { Performance by } \\
\text { Similarity to Ideal } \\
\text { Solution } \\
\text { (TOPSIS) }\end{array}$ & $\begin{array}{l}\text { Construction of the model and comparisons between alternatives and criteria, } \\
\text { reduction of the number of comparisons and priorization of the alternatives. } \\
\text { Shyur and Shih (2006). }\end{array}$ \\
\hline $\begin{array}{l}\text { ANP/Benefits, } \\
\text { Opportunities, } \\
\text { Costs and Risks } \\
\text { (BOCR) }\end{array}$ & $\begin{array}{l}\text { The criteria and its relations of dependence were defined under the BOCR } \\
\text { merits. } \\
\text { Tan et al. (2007). }\end{array}$ \\
\hline $\begin{array}{l}\text { ANP/Multi } \\
\text { Objective Mixed } \\
\text { Integer Linear } \\
\text { Programming } \\
\text { (MOMILP), } \\
\text { ANP/Goal } \\
\text { programming } \\
\text { (GP) }\end{array}$ & $\begin{array}{l}\text { Evaluation and classification of the suppliers according to } 14 \text { criteria that are } \\
\text { involved with BOCR merits / Inclusion of the Objective Functions and of } \\
\text { restrictions with several finalities, for instance: find the optimal quantities of } \\
\text { requests among the selected suppliers. } \\
\text { Demirtas and Ustun (2007), Ustun and Demirtas (2007), Ustum and Demirtas } \\
\text { (2008), Demirtas and Ustun (2008). }\end{array}$ \\
\hline $\begin{array}{l}\text { ANP/Mixed } \\
\text { Integer } \\
\text { Programming } \\
\text { (MIP) }\end{array}$ & $\begin{array}{l}\text { The ANP results were used as Objective Function coefficients (to minimize cost) } \\
\text { of MIP (Mathematical Integer Programming) so as to allocate optimal amounts } \\
\text { of request for each supplier. } \\
\text { Wu, Sukoco and Li (2008). }\end{array}$ \\
\hline
\end{tabular}

The main contribution of this work is to introduce Ratings to ANP method at the Stage 4 of the SSP framework proposed. It shall be considered a problem - illustrative example - with qualitative and quantitative criteria. Besides, ANP is destined to the choice problem (P. $\alpha$ ) which consists into formulate the decision problem in such a way to choose the better or the best alternatives, and, different from other methods allows dependence relations between criterion and alternatives thus making the model more realistic. Next, it will be described the ANP method, which shall be used in the illustrative example.

\subsection{Analytic Network Process - ANP}

Developed by Thomas L. Saaty in 1996, Analytic Network Process (ANP) is a method pertaining to the American School of Multiple Criteria Decision Making (MCDM). Considered a generalization of the Analytic Hierarchy Process (AHP), the ANP, uses a grid (instead of hierarchy) without the necessity to specify levels, besides allowing relations of dependence between its clusters and elements (nodes) (SAATY, 2005).

The ANP method applied to a decision problem already formulated considers the following stages: 1) Formulation of the problem, 2) Judgments and, 3) Algebraic development. Figure 3 presents a Fluxogram with the steps contained in these stages. For more details, see Saaty (2005).

\section{Stage 1: Formulation of the problem}

- Step 1 - Structuring of the problem: in this pace is advisable the use of a method to structure the problem which shall give support to the decision taker to define the objective of the decisory process, the clusters, elements or nodes and the alternatives to solve the problem.

- Step 2 - Construction of the grid: one identifies the grid of clusters and elements, and the relations of dependence and feedback are established between them. 


\section{Stage 2: Judgements}

- Step 1 - Construction of the matrices of global and local reachability: the aim is to visualize the existence of dependence relations in the grid, established in step 1. That is, the matrix of global reachability shows if there is or not existence of dependence relations between distinct clusters or in a same cluster (loop). The matrix of local reachability shows the existence of dependence relations among the elements of every cluster of the grid. In both matrices, it shall be given the value 1 if there is relation or dependence otherwise, zero.

- Step 2 - Pairwise comparisons of the elements and of the clusters interconnected: comparisons are made for every connections existing in the grid, according to Saaty's Fundamental Scale. Comparisons divide itself in two cases: a) comparisons between elements (or nodes) of each cluster; and, b) comparisons among clusters. In the first case, the comparisons to be made are those in which a node has relation of dependence with at least two nodes of a cluster. In second case, the comparison is made among clusters in which there is relation of dependence.

- Step 3 - Verification of judgements consistency: after comparisons, it is relevant to verify the decisor's judgements consistency in both cases. In case that judgements are not consistent, it may have occurred a mistake in the judgments or in the formulation of the problem, making it necessary to correct the pairwise comparisons or in the formulation of the problem. However, being the judgments consistent, the next step could be executed.

- Step 4 - Obtainment of the eigenvectors and Cluster weights matrix: from such comparisons, it's possible to obtain the eigenvectors of priorities and Cluster weights matrix, respectively.

\section{Stage 3: Algebraic development}

- Step 1 - Construction of the Unweighted Supermatrix: it is composed by vectors of priorities placed in columns, obtained by pairwise comparisons came from the relations of dependence among the elements.

- Step 2 - Obtainment of the Weighted Supermatrix: origins by multiplying the Cluster weights matrix (matrix made of the eigenvectors of priorities from the comparisons among clusters) by the Unweighted Supermatrix. The same must be stochastic in relation to the columns (sum of the elements of the column gives 1).

- Step 3 - Verification if the Weighted Supermatrix is stochastic: in case the Weighted Supermatrix obtained is not stochastic in relation to the columns, it must normalize in relation to the columns to make it stochastic.

- Step 4 - Obtainment of the Limit Matrix: obtained by increasing the Weighted Supermatrix to sucessive powers until it convergence, that is, when every column of the matrix has the same values. The Limit Matrix must also be stochastic in relation to the columns and in it is possible to observe the final result.

- Step 5 - Final result: performed the previous steps, you obtain the final result with the priority ranking of the alternatives. 


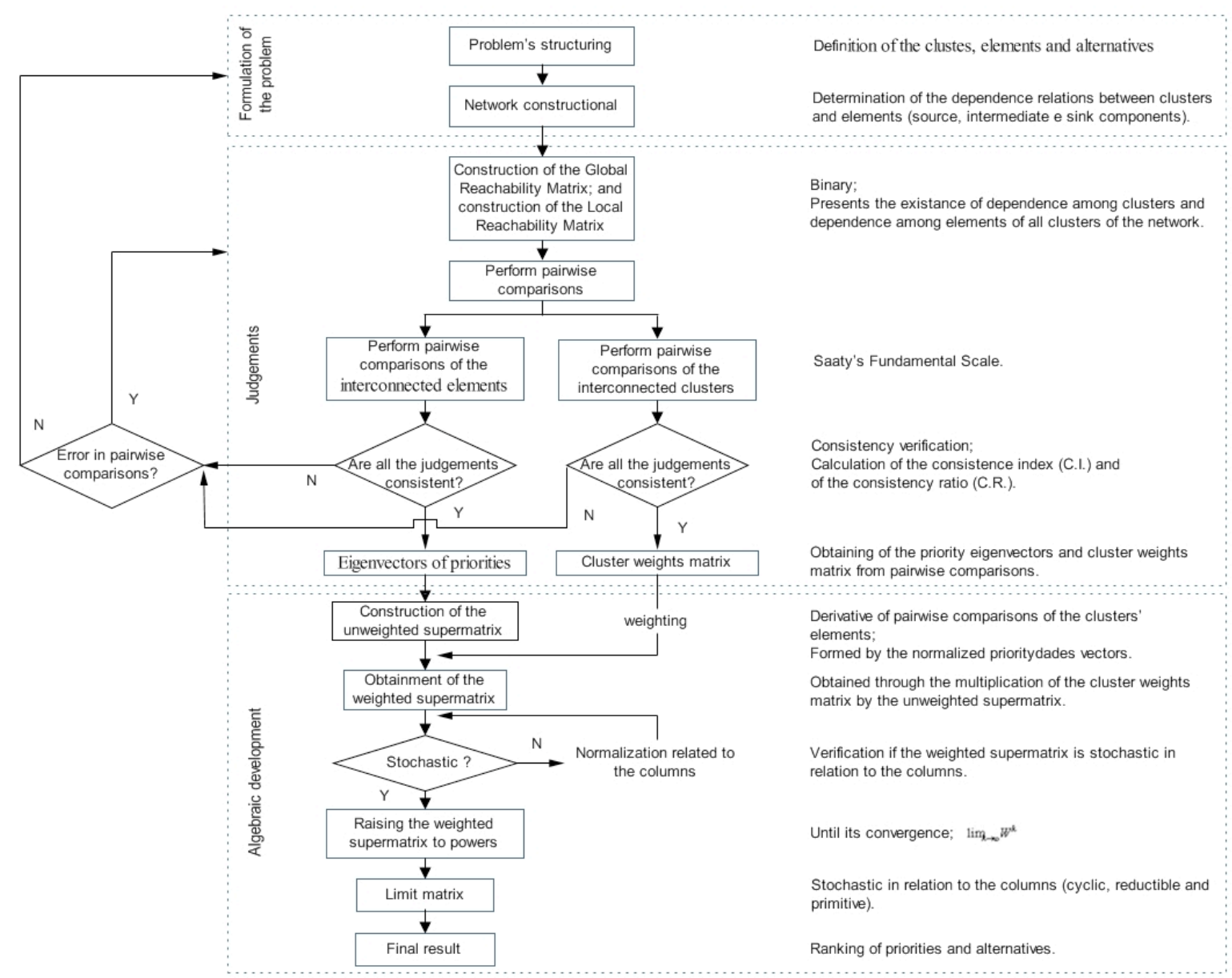

Figure 3: Steps followed in the ANP (source: authors).

At the ANP when the elements of the network are classified in categories of intensities according to its characteristics and the alternatives are evaluated individually before each element, it is known as Ratings model. The criteria receive categories of intensities, such as: high, average and low; excellent, very good, good, regular and weak; more than 15 years, between 10 and 15 years, between 5 and 10 years and less than 5 years. In this kind of model the alternatives will be evaluated according to their performance in each criterion.

The advantage of ANP model with Ratings use is when the alternatives are numerous, for it reduces the number of judgements required. Yet, Ratings model are very well appropriated in environments where people with knowledge or specialists have given the evaluation structure.

At the next section, it shall be presented a fictious illustrative example with the aim to apply the proposed method, ANP with Ratings.

\section{Illustrative Example}

The illustrative example context is as follows: it is assumed that a certain company wishes to acquire a lot of a product. For this product, there are 10 suppliers known. The decisors in this illustrative example are the authors of the work themselves. The decision in this case is about choice, or selection, of which supplier the lot must be bought.

\subsection{Application of the ANP for the illustrative example}

It is assumed that the decision problem is previously structured. Next, it was identified, through a bibliography research, the criteria more commonly used in the SSP. Then, the network of the problem 
in question was built and was determined the dependence relations between clusters and elements or nodes.

\section{Stage 1: Formulation of the problem}

Figure 4 presents the clusters and elements of SSP illustrative example. It was considered three clusters (Capability, Green Competencies and Performance), being each one composed by its respective elements.

The ANP method allows dependence relations between elements and clusters. Such relations are represented by arrows, when the dependence occurs between a cluster over another cluster, or through a loop, when there is dependence among elements of a same cluster. In order to exist an arrow from a cluster to another, it's enough that at least one element of the original cluster is connected to an element of the destination cluster (SAATY, 2005). This way, with the possibility to analyse dependences among criteria and influences among alternatives, ANP method was applied with the help of the free Software SuperDecisions (www.superdecisions.com), following the stages and steps in Figure 3.

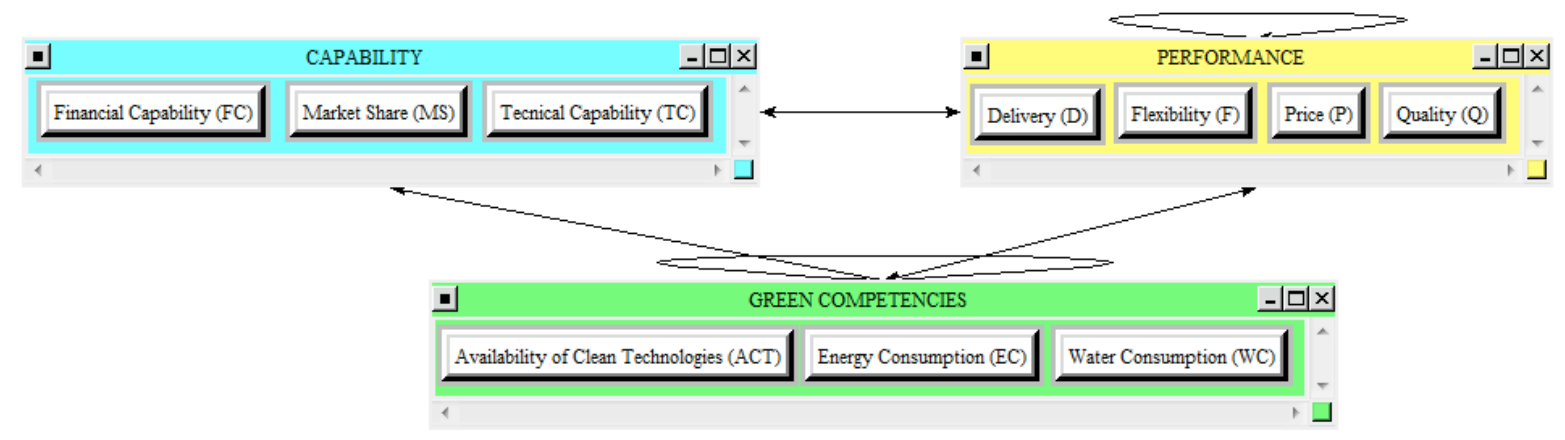

Figure 4: The clusters and elements of SSP illustrative example.

The three clusters with its respective elements are written next.

The Cluster Capability is formed by the elements:

- Financial capability (FC), classified in: stable and unstable;

- Market Share (MS), classified as: $>60 \%, 30-60 \%$ e $<30 \%$;

- Technical competence (TC), if it is qualified and disqualified.

The Cluster Green Competencies comprehends:

- Availability of clean technology (ACT), which is classified as: possess and do not possess;

- Energy consumption (EC) and Water Consumption (WC) that are classified in: high, average and low.

The Cluster Performance:

- Deliver (D) is classified as: fast, moderate and delay;

- Flexibility (F) is classified as: good and bad;

- Price $(\mathrm{P})$ is classified as: high, average and good;

- Quality (Q) is classified as: great, good and bad;

The Ratings use is valid when is necessary to establish standards for the numerous alternatives, for it reduces the number of judgements required. The suppliers' performance in each criterion may be shortened according to Table 2 .

Table 2. Suppliers and ratings according to the elements 


\begin{tabular}{|l|l|l|l|l|l|}
\hline Supplier & $\begin{array}{l}\text { Financial } \\
\text { capability (FC) }\end{array}$ & $\begin{array}{l}\text { Market share } \\
\text { (MS) }\end{array}$ & $\begin{array}{l}\text { Tecnical } \\
\text { capability (TC) }\end{array}$ & $\begin{array}{l}\text { Availability of clean } \\
\text { Technologies (ACT) }\end{array}$ & $\begin{array}{l}\text { Energy consumption } \\
\text { (EC) }\end{array}$ \\
\hline S1 & Stable & $>60 \%$ & Qualified & Do not possess & Average \\
\hline S2 & Stable & $30-60 \%$ & Qualified & Do not possess & Average \\
\hline S3 & Unstable & $<30 \%$ & Qualified & Possess & Low \\
\hline S4 & Stable & $<30 \%$ & Qualified & Possess & Low \\
\hline S5 & Stable & $30-60 \%$ & Qualified & Do not possess & High \\
\hline S6 & Unstable & $<30 \%$ & Disqualified & Do not possess & Average \\
\hline S7 & Stable & $<30 \%$ & Qualified & Possess & Low \\
\hline S8 & Stable & $>60 \%$ & Qualified & Possess & Low \\
\hline S9 & Stable & $<30 \%$ & Qualified & Do not possess & High \\
\hline S10 & Stable & $30-60 \%$ & Qualified & Possess & Low \\
\hline & $\begin{array}{l}\text { Water } \\
\text { consumption } \\
\text { (WC) }\end{array}$ & $\begin{array}{l}\text { Delivery } \\
\text { (D) }\end{array}$ & $\begin{array}{l}\text { Flexibility } \\
\text { (F) }\end{array}$ & $\begin{array}{l}\text { Price } \\
\text { (P) }\end{array}$ & $\begin{array}{l}\text { Quality } \\
\text { (Q) }\end{array}$ \\
\hline Supplier & Average & Fast & Good & Average & Great \\
\hline S1 & Moderate & Good & Average & Good \\
\hline S2 & Average & Slow & Bad & Good & Good \\
\hline S3 & Low & Moderate & Bad & High & Good \\
\hline S4 & Low & Moderate & Good & Average & Good \\
\hline S5 & High & Slow & Bad & Good & Bad \\
\hline S6 & Average & Moderate & Good & High & Great \\
\hline S7 & Low & Fast & Good & High & Great \\
\hline S8 & Low & Moderate & Bad & High & Great \\
\hline S9 & High & Fast & Good & High & Great \\
\hline S10 & Low & & & \\
\hline & & & & \\
\hline
\end{tabular}

\section{Stage 2: Judgements}

Once the problem is formulated and the network built and validated begins the judgement stage, in which the decisors express their preferences, through the construction of the comparison matrices of the clusters, elements and Ratings, according to Saaty's Fundamental Scale.

The comparisons to be made are those in which a element of a cluster has relation of dependence with at least two elements of another cluster. Besides, one made the pairwise comparison of each element with relation to the adopted Ratings. Table 3 refers to the suppliers and their performance in the respective categories, in the way of numerical equivalences obtained after the comparisons of the Ratings.

Table 3. Suppliers and numerical equivalence of the ratings according to the elements

\begin{tabular}{|l|l|l|l|l|l|l|l|l|l|l|l|}
\hline $\begin{array}{l}\text { Priorities } \\
\text { (Limits) }\end{array}$ & 0.0648 & 0.1625 & 0.1345 & 0.0815 & 0.0355 & 0.0666 & 0.0179 & 0.0083 & 0.1996 & 0.2288 & \\
\hline & FC & MS & TC & ACT & EC & WC & D & F & P & Q & Totals \\
\hline S1 & 1.0000 & 1.0000 & 1.0000 & 0.1429 & 0.3952 & 0.3952 & 1.0000 & 1.0000 & 0.3952 & 1.0000 & 0.7477 \\
\hline S2 & 1.0000 & 0.3952 & 1.0000 & 0.1429 & 0.3952 & 0.3952 & 0.3952 & 1.0000 & 0.3952 & 0.3952 & 0.5002 \\
\hline S3 & 0.1428 & 0.0937 & 1.0000 & 1.0000 & 1.0000 & 1.0000 & 0.0937 & 0.1429 & 1.0000 & 0.3952 & 0.6354 \\
\hline S4 & 1.0000 & 0.0937 & 1.0000 & 1.0000 & 1.0000 & 1.0000 & 0.3952 & 0.1429 & 0.0937 & 0.3952 & 0.5155 \\
\hline S5 & 1.0000 & 0.3952 & 1.0000 & 0.1429 & 0.0937 & 0.0937 & 0.3952 & 1.0000 & 0.3952 & 0.3952 & 0.4694 \\
\hline S6 & 0.1428 & 0.0937 & 0.1428 & 0.1429 & 0.3952 & 0.3952 & 0.0937 & 0.1429 & 1.0000 & 0.0937 & 0.3196 \\
\hline S7 & 1.0000 & 0.0937 & 1.0000 & 1.0000 & 1.0000 & 1.0000 & 0.3952 & 1.0000 & 0.0937 & 1.0000 & 0.6610 \\
\hline S8 & 1.0000 & 1.0000 & 1.0000 & 1.0000 & 1.0000 & 1.0000 & 1.0000 & 1.0000 & 0.0937 & 1.0000 & 0.8191 \\
\hline S9 & 1.0000 & 0.9372 & 1.0000 & 0.1429 & 0.0937 & 0.0937 & 0.3952 & 0.1429 & 0.0937 & 1.0000 & 0.4915 \\
\hline S10 & 1.0000 & 0.3952 & 1.0000 & 1.0000 & 1.0000 & 1.0000 & 1.0000 & 1.0000 & 0.0937 & 1.0000 & 0.7208 \\
\hline
\end{tabular}


Table 4 illustrates a example of pairwise comparison matrix among the elements of the Cluster Capability with respect to element Quality. It is evident that the TC has higher influence with a priority of 0,588 ; followed by MS, with priority 0,323 .

Table 4. Pairwise comparison matrix among elements of the Cluster Capability with respect to element Quality

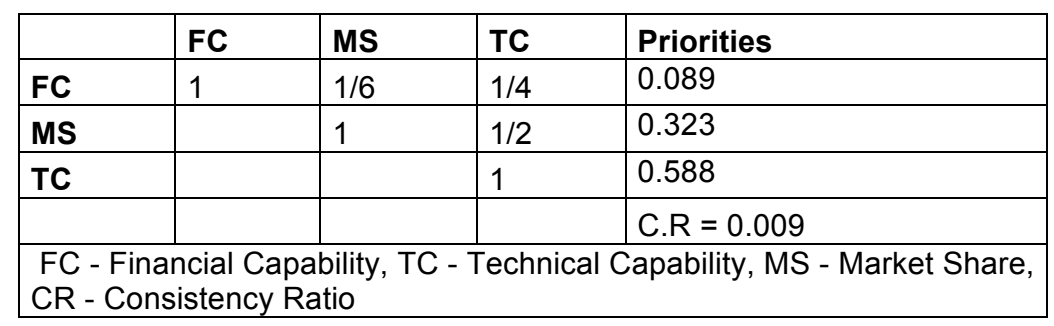

Table 5 presents the eigenvectors obtained from the pairwise comparisons of the clusters (Cluster weights matrix). There, it is possible to observe how much the clusters are influenced by another cluster. For instance, the Cluster Capability influences the Cluster Green Competencies $(0,1220)$, and the Cluster Performance $(0,1220)$. Once there exists a inner dependence (loop) in the Cluster Performance it suffers influence of itself $(0,6483)$. The Cluster Capability is influenced by all other clusters, except for itself (Figure 3). However, still receives value zero from the influence of the Cluster Green Competencies for it influences a single element, with no comparison, therefore. Besides, the cluster that possess higher importance is the Cluster Performance according to the weight vectors $[0.1220,0.2297,0.6483]^{\mathrm{T}}$ for the Clusters Capability, Green Competencies e Performance, respectively.

Table 5. Cluster weights matrix

\begin{tabular}{|l|l|l|l|}
\hline & $\begin{array}{l}\text { Cluster } \\
\text { Capability }\end{array}$ & $\begin{array}{l}\text { Cluster Green } \\
\text { Competencies }\end{array}$ & $\begin{array}{l}\text { Cluster } \\
\text { Performance }\end{array}$ \\
\hline Cluster Capability & 0.0000 & 0.1220 & 0.1220 \\
\hline Cluster Green Competencies & 0.0000 & 0.2297 & 0.2297 \\
\hline Cluster Performance & 1.0000 & 0.6483 & 0.6483 \\
\hline
\end{tabular}

\section{Stage 3: Algebraic development}

Implemented the network structure and made the pairwise comparisons, and following the Figure 3, the Unweighted and Weighted Supermatrices and Limit Matrix are built, according Tables 6, 7 e 8, respectively.

The Unweighted Supermatrix (Table 6) is composed by priority vectors placed in columns, obtained by pairwise comparisons came from the dependence relations. For instance, the vector of priority obtained in Table 4, may be visualized in the last column of the supermatrix. The number of priorities in each column represents the number of comparisons of the element corresponding to that column.

The Weighted Supermatrix (Table 7), by it turn, origins by multiplying the weights of the clusters (Table 5) by its corresponding blocks of the Unweighted Supermatrix (Table 6), obtaining a stochastic matrix, that is, the sum of every column is 1 . The zeros indicate absence of interaction, for instance, FC does not influence D. On the other side, D $(0,1061)$ and F $(0,0513)$ influence MS.

The Limit Matrix (Table 8) is obtained by increasing the Weighted Supermatrix to successive powers until it convergence. All priorities are stable. One observes that the values different from zero, found in the columns, repeat themselves. 
Table 6. Unweighted Supermatrix

\begin{tabular}{|c|c|c|c|c|c|c|c|c|c|c|c|}
\hline & & \multicolumn{3}{|c|}{ Cluster Capability } & \multicolumn{3}{|c|}{$\begin{array}{l}\text { Cluster Green } \\
\text { Competencies }\end{array}$} & \multicolumn{4}{|c|}{ Cluster Performance } \\
\hline & & FC & MS & TC & ACT & EC & wC & D & $\mathbf{F}$ & $\mathbf{P}$ & $\mathbf{Q}$ \\
\hline \multirow{3}{*}{ 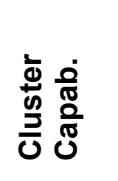 } & FC & 0.0000 & 0.0000 & 0.0000 & 1.0000 & 1.0000 & 1.0000 & 0.0000 & 0.0000 & 0.0000 & 0.0890 \\
\hline & MS & 0.0000 & 0.0000 & 0.0000 & 0.0000 & 0.0000 & 0.0000 & 1.0000 & 1.0000 & 1.0000 & 0.3234 \\
\hline & TC & 0.0000 & 0.0000 & 0.0000 & 0.0000 & 0.0000 & 0.0000 & 0.0000 & 0.0000 & 0.0000 & 0.5876 \\
\hline \multirow{3}{*}{ 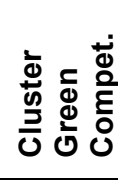 } & ACT & 0.0000 & 0.0000 & 0.0000 & 0.0000 & 0.0000 & 0.0000 & 0.0000 & 0.0000 & 0.6250 & 0.0000 \\
\hline & EC & 0.0000 & 0.0000 & 0.0000 & 0.3333 & 0.0000 & 0.0000 & 0.0000 & 0.0000 & 0.1365 & 0.0000 \\
\hline & WC & 0.0000 & 0.0000 & 0.0000 & 0.6667 & 0.0000 & 0.0000 & 0.0000 & 0.0000 & 0.2385 & 0.0000 \\
\hline \multirow{4}{*}{ 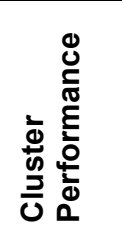 } & D & 0.0000 & 0.1061 & 0.0000 & 0.0000 & 0.0000 & 0.0000 & 0.0000 & 0.0936 & 0.0000 & 0.0000 \\
\hline & $\mathbf{F}$ & 0.0000 & 0.0513 & 0.0000 & 0.0000 & 0.0000 & 0.0000 & 0.0000 & 0.0000 & 0.0000 & 0.0000 \\
\hline & $\mathbf{P}$ & 1.0000 & 0.2889 & 0.0000 & 0.0000 & 1.0000 & 1.0000 & 0.0000 & 0.2797 & 0.0000 & 0.0000 \\
\hline & $\mathbf{Q}$ & 0.0000 & 0.5537 & 1.0000 & 0.0000 & 0.0000 & 0.0000 & 0.0000 & 0.6267 & 0.0000 & 0.0000 \\
\hline
\end{tabular}

Table 7. Weighted Supermatrix

\begin{tabular}{|c|c|c|c|c|c|c|c|c|c|c|c|}
\hline & & \multicolumn{3}{|c|}{ Cluster Capability } & \multicolumn{3}{|c|}{$\begin{array}{l}\text { Cluster } \\
\text { Competencies }\end{array}$} & \multicolumn{4}{|c|}{ Cluster Performance } \\
\hline & & FC & MS & TC & ACT & EC & wC & D & $\mathbf{F}$ & $\mathbf{P}$ & $\mathbf{Q}$ \\
\hline \multirow{3}{*}{$\begin{array}{l}\bar{\Phi} \\
\frac{0}{\pi} \\
\frac{0}{0} \\
\frac{0}{0} \\
\end{array}$} & FC & 0.000 & 0.0000 & 0.0000 & 0.3470 & 0.1584 & 0.1584 & 0.000 & 0.0000 & 0.0000 & 0.0890 \\
\hline & MS & 0.000 & 0.0000 & 0.0000 & 0.000 & 0.0000 & 0.0000 & 1.000 & 0.1584 & 0.3470 & 0.3234 \\
\hline & TC & 0.000 & 0.0000 & 0.00000 & 0.000 & 0.0000 & 0.0000 & 0.000 & 0.0000 & 0.0000 & 0.5876 \\
\hline \multirow{3}{*}{ 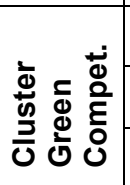 } & ACT & 0.000 & 0.0000 & 0.0000 & 0.000 & 0.0000 & 0.0000 & 0.000 & 0.0000 & 0.4082 & 0.000 \\
\hline & EC & 0.000 & 0.0000 & 0.0000 & 0.2177 & 0.000 & 0.0000 & 0.000 & 0.0000 & 0.0891 & 0.000 \\
\hline & WC & 0.000 & 0.0000 & 0.0000 & 0.4354 & 0.000 & 0.0000 & 0.000 & 0.0000 & 0.1557 & 0.000 \\
\hline \multirow{4}{*}{ 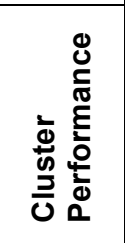 } & D & 0.0000 & 0.1061 & 0.0000 & 0.000 & 0.0000 & 0.0000 & 0.0000 & 0.0788 & 0.0000 & 0.0000 \\
\hline & $\mathbf{F}$ & 0.0000 & 0.0513 & 0.0000 & 0.000 & 0.0000 & 0.0000 & 0.000 & 0.0000 & 0.0000 & 0.000 \\
\hline & $\mathbf{P}$ & 1.0000 & 0.2889 & 0.0000 & 0.000 & 0.8416 & 0.8416 & 0.0000 & 0.2354 & 0.0000 & 0.0000 \\
\hline & $\mathbf{Q}$ & 0.0000 & 0.5537 & 1.0000 & 0.000 & 0.000 & 0.0000 & 0.0000 & 0.5274 & 0.0000 & 0.0000 \\
\hline
\end{tabular}


Tabela 8. Limit Matrix

\begin{tabular}{|c|c|c|c|c|c|c|c|c|c|c|c|}
\hline & & \multicolumn{3}{|c|}{ Cluster Capability } & \multicolumn{3}{|c|}{$\begin{array}{l}\text { Cluster } \\
\text { Competencies }\end{array}$} & \multicolumn{4}{|c|}{ Cluster Performance } \\
\hline & & FC & MS & TC & ACT & EC & wc & D & $\mathbf{F}$ & $\mathbf{P}$ & $\mathbf{Q}$ \\
\hline \multirow{3}{*}{ 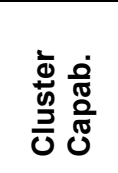 } & FC & 0.0648 & 0.0648 & 0.0648 & 0.0648 & 0.0648 & 0.0648 & 0.0648 & 0.0648 & 0.0648 & 0.0648 \\
\hline & MS & 0.1625 & 0.1625 & 0.1625 & 0.1625 & 0.1625 & 0.1625 & 0.1625 & 0.1625 & 0.1625 & 0.1625 \\
\hline & TC & 0.1345 & 0.1345 & 0.1345 & 0.1345 & 0.1345 & 0.1345 & 0.1345 & 0.1345 & 0.1345 & 0.1345 \\
\hline \multirow{3}{*}{ 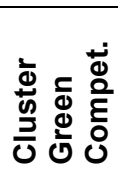 } & ACT & 0.0815 & 0.0815 & 0.0815 & 0.0815 & 0.0815 & 0.0815 & 0.0815 & 0.0815 & 0.0815 & 0.0815 \\
\hline & EC & 0.0355 & 0.0355 & 0.0355 & 0.0355 & 0.0355 & 0.0355 & 0.0355 & 0.0355 & 0.0355 & 0.0355 \\
\hline & WC & 0.0666 & 0.0666 & 0.0666 & 0.0666 & 0.0666 & 0.0666 & 0.0666 & 0.0666 & 0.0666 & 0.0666 \\
\hline \multirow{4}{*}{ 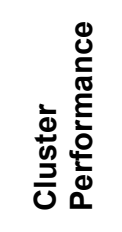 } & D & 0.0179 & 0.0179 & 0.0179 & 0.0179 & 0.0179 & 0.0179 & 0.0179 & 0.0179 & 0.0179 & 0.0179 \\
\hline & $\mathbf{F}$ & 0.0083 & 0.0083 & 0.0083 & 0.0083 & 0.0083 & 0.0083 & 0.0083 & 0.0083 & 0.0083 & 0.0083 \\
\hline & $\mathbf{P}$ & 0.1996 & 0.1996 & 0.1996 & 0.1996 & 0.1996 & 0.1996 & 0.1996 & 0.1996 & 0.1996 & 0.1996 \\
\hline & $\mathbf{Q}$ & 0.2288 & 0.2288 & 0.2288 & 0.2288 & 0.2288 & 0.2288 & 0.2288 & 0.2288 & 0.2288 & 0.2288 \\
\hline
\end{tabular}

\subsection{Discussion of the results}

Table 9 presents the priorities of each element normalized by cluster and priorities from limiting matrix. The values of the column "Priorities from limiting matrix" come from the Limit Matrix. Represent the global priority with respect to the integer model, adding 1 . Such values normalized by a cluster origin the column "Priorities normalized by cluster", in such way that the priorities of each cluster give 1.

The elements MS, ACT and Q presented the higher priorities in the Clusters Capability, Green Competencies and Performance, respectively. In Cluster Capability the highest priorities were given to the elements MS and TC.

In the Cluster Green Competencies, the elements of higher weights were: ACT e WC. This comes from the judgements of the decisors that gave a higher importance to the use of clean technology and to the consumption of water. Both elements are very influent nowadays for much has been told about environment maintainability.

With relation to the Cluster Performance, the elements of higher weights are Q and $\mathrm{P}$ which are relevant for the suppliers' selection process. Therefore, each element obtained a priority that represents its importance in the selection of supplier for the company. 
Table 9. Normalized by cluster priorities and limiting priorities

\begin{tabular}{|c|c|c|c|}
\hline & & $\begin{array}{l}\text { Priorities } \\
\text { normalized } \\
\text { by cluster }\end{array}$ & $\begin{array}{l}\text { Priorities from } \\
\text { limiting matrix }\end{array}$ \\
\hline \multirow{3}{*}{ 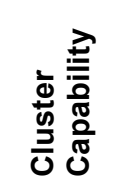 } & FC & 0.1791 & 0.0648 \\
\hline & MS & 0.4492 & 0.1625 \\
\hline & TC & 0.3717 & 0.1345 \\
\hline \multirow{3}{*}{ 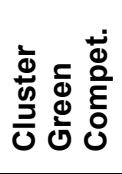 } & ACT & 0.4439 & 0.0815 \\
\hline & EC & 0.1936 & 0.0355 \\
\hline & WC & 0.3626 & 0.0666 \\
\hline \multirow{4}{*}{ 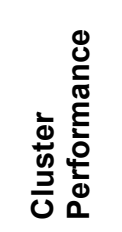 } & D & 0.0394 & 0.0179 \\
\hline & $\mathrm{F}$ & 0.0183 & 0.0083 \\
\hline & $P$ & 0.4391 & 0.1996 \\
\hline & $\mathbf{Q}$ & 0.5032 & 0.2288 \\
\hline
\end{tabular}

The final ranking of the suppliers is presented in Figure 4. In this fictitious illustrative example, the supplier that presents a higher proportion of the ranking is the Supplier 8, followed by suppliers 1, 10, $7,3,4,2,9,5$ e 6 .

\begin{tabular}{|c|c|c|c|c|}
\hline Name & Graphic & Ideals & Normals & Raw \\
\hline Supplier 1 & & 0.912822 & 0.127151 & 0.127151 \\
\hline Supplier 2 & & 0.610675 & 0.085064 & 0.085064 \\
\hline Supplier 3 & & 0.775821 & 0.108068 & 0.108068 \\
\hline Supplier 4 & & 0.629330 & 0.087662 & 0.087662 \\
\hline Supplier 5 & & 0.573094 & 0.079829 & 0.079829 \\
\hline Supplier 6 & & 0.390237 & 0.054358 & 0.054358 \\
\hline Supplier 7 & & 0.806993 & 0.112410 & 0.112410 \\
\hline Supplier 8 & & 1.000000 & 0.139295 & 0.139295 \\
\hline Supplier 9 & & 0.600038 & 0.083582 & 0.083582 \\
\hline Supplier 10 & & 0.880018 & 0.122582 & 0.122582 \\
\hline
\end{tabular}

Figure 4: Synthesized results.

The column "Raw" represents the priorities of the alternatives derived from the normalization of the column "Totals" of Table 3 . In this case, the column "Raw" is equal to the column "Normals" due to the fact that it already adds 1 . The column "Ideals" is obtained by dividing every element of this column by its higher value.

Despite the simplicity of the illustrative example, it is important the application of the ANP method for the SSP, especially in presence of many suppliers, cluster and elements.

\section{Final Considerations}

Currently, the globalization and the competitiveness has demanded that the supplies chain become more efficient. And the appropriate choice of the supply is relevant for a production of good quality and low cost. Inadequate selection of suppliers brings unsatisfaction to costumer and prejudice to company as well.

Multiple Criteria Decision Making methods (MCDM), being among them the ANP, has been much appropriated for the SSP solution. ANP is characterized for including qualitative and quantitative criteria, structured in network, where the dependence relations among elements are allowed. 
The implementation of the Ratings model in the ANP consists in giving categories to the criteria in order to classify the alternatives, so as to select the best suppliers. With the advantages to allow the reduction of the number of judgements required to the decisor and allows the analysis of cases in which the alternatives are numerous. Besides making possible the insertion and retreat of alternatives during the decisory process, without causing inversion of ranking. Such characteristics are advantageous as they allow the representation of a complex problem of supplier selection, making it more realistic.

However, there isn't a better way to evaluate and select suppliers. Therefore the organizations use a variety of different models, adapting the best according to the specific requisites of the company. The model must be able to adequate the results to a set of changing associated among different suppliers and be able to deal such as good as with qualitative and quantitative data.

The proposition of this work was to present a method to be used in the stage of final selection of suppliers of the SSP's framework. For future works, we suggest the combined implementation of the models Ratings and BOCR (Benefits, Opportunities, Costs and Risks) to the ANP method for the SSP.

\section{REFERENCES}

Araz, C. e Ozkarahan, I. (2007). Supplier evaluation and management system for strategic sourcing based on a new multicriteria sorting procedure. International Journal of Production Economics, 106, 585-606.

Bayazit, O. (2006). Use of analytic network process in vendor selection decisions, Benchmarking: An International Journal, 13, 566-579.

Bello M. J. S. (2003). A case study approach to the supplier selection process. Master of Engineering in Management Systems Engineering. University of Puerto Rico, Mayagüez Campus.

Boer, L. de, van der Wegen, L. e Telgen, J. (1998). Outranking methods in support of supplier selection. European Journal of Purchasing \& Supply Management, 4, 109-118.

Boer, L. de, Labro, E. e Morlacchi, P. (2001). A review of methods supporting supplier selection, European Journal of Purchasing \& Supply Management, 7, 75-89.

Boer, L. de e van der Wegen, L.L.M. (2003). Practice and promise of formal supplier selection: a study of four empirical cases. Journal of Purchasing and Supply Management, 9, 109-118.

Cheraghi, S. H., Dadashzadeh, M. e Subramanian, M. (2001) Critical success factors for supplier selection: an update. Journal of Applied Business Research 20(2), 91-108.

Croom, S. R. (2001). The dyadic capabilities concept: examining the processes of key supplier involvement in collaborative product development. European Journal of Purchasing \& Supply Management , 7, 29-37.

Güner H., Mutlu Ö. e Kulak O. (2007). Supplier Selection in Fuzzy Environment. 35th International Conference on Computers and Industrial Engineering, 1, 838-844.

Korpela, J., Lehmusvaara, A.; Tuominen, M. (2001). Customer service based design of the Supply chain. International Journal of Production Economics, 69, 193-204. 
Lee, C. C. e Ou-Yang, C. (2008). A neural networks approach for forecasting the supplier's bid prices in supplier selection negotiation process. Expert Systems with Applications, doi: 10.1016/j.eswa.2008.01.063.

Nascimento, L. P. A. da S.; Silva, A. C. S. e Belderrain, M. C. N. (2008). Revisão de literatura sobre a aplicação do método ANP ao problema de seleção de fornecedores. Atas do XL SBPO, v.1.

Onesime, O. C. T., Xiaofei, X. e Dechen, Z. (2004). A Decision Support System for Supplier Selection Process. International Journal of Information Technology \& Decision Making, 3, 453-470.

Ribeiro, J. R. et al. (2007). Multiple criteria methods applied to select suppliers of a capital goods company. Proceedings ISAHP 2007, Viña Del Mar, Chile, 1-10.

Saaty, T. L. (2005). Theory and Applications of the Analytic Network Process. Pittsburgh, PA: RWS Publications.

Saen, R. F. (2007). Suppliers selection in the presence of both cardinal and ordinal data. European Journal of Operational Research, 183, 741-747.

Silva, A. C. S.; Nascimento, L. P. A. S. e Belderrain, M. C. N. (2008). Supplier Selection Problem (SSP): estado-da-arte. XIV Congresso Latino-Ibero_Americano en Investigación de Operaciones (CLAIO), Cartagena, Colombia, v.1.

Sonmez, M. (2006). A review and critique of supplier selection process and practices. Business School Occasional Papers Series, 1, 1-34.

Super Decisions Software, versão 1.6.0: Creative Decisions Foundation, Pittsburgh, 2005. Disponível na internet (www.superdecisions.com).

Tahriri, F. et al. (2008). A Review of Supplier Selection Methods in Manufacturing Industries. Journal of Science and Technology. 15(3), 201-2008.

Wang, G., Huang, S. H. e Dismukes, J. P. (2004). Product-driven supply chain selection using integrated multi-criteria decision-making methodology. International Journal of Production Economics, 91, 1-15. 